\title{
Orosomucoid can predict baseline peritoneal transport characteristics in peritoneal dialysis patients and reduce peritoneal proteins loss
}

\section{Manchen Bao \\ Zhongshan Hospital Fudan University \\ Zhaoxing Sun \\ Zhongshan Hospital Fudan University \\ Xiaoxiao Yang \\ Zhongshan Hospital Fudan University \\ Jun Ji \\ Zhongshan Hospital Fudan University \\ Lin Zhang \\ Zhongshan Hospital Fudan University \\ Bo Xiang \\ Zhongshan Hospital Fudan University \\ Guoquan Yan}

Key Laboratory of Metabolism and Molecular Medicine, Ministry of Education, and Department of Biochemistry and Molecular Biology, School of Basic Medical Sciences, and Institutes of Biomedical Sciences, Fudan University

Xiaoqiang Ding

Zhongshan Hospital, Fudan University

\section{Jianzhou Zou}

Zhongshan Hospital, Fudan University

Xiaofang Yu ( $\sim$ yu.xiaofang@zs-hospital.sh.cn )

Zhongshan Hospital, Fudan University

\section{Research}

Keywords: Peritoneal dialysis, Peritoneal transport, Proteomics, Orosomucoid, C-reactive protein

Posted Date: November 4th, 2020

DOI: https://doi.org/10.21203/rs.3.rs-100253/v1

License: (c) (i) This work is licensed under a Creative Commons Attribution 4.0 International License. Read Full License

Version of Record: A version of this preprint was published at Journal of Proteomics on June 1st, 2021. See the published version at https://doi.org/10.1016/j.jprot.2021.104260. 


\section{Abstract}

Background: Peritoneal dialysis (PD) is a kind of replacement therapies for end-stage renal disease (ESRD) patients. In the first 4-8 weeks of PD therapy, the patients were given an empirical dialysis prescription due to unknown peritoneal transport characteristics.

Methods:खProteomic analysis was used to identify serum biomarkers which can predict the baseline peritoneal transport characteristics.

Results: A discovery set of serum samples from ESRD patients were collected. After 4-8 weeks of PD therapy, these patients were divided into three groups according to the peritoneal equilibration test (PET) results: high (H), high average (HA), low average and low (LA\&L) transporters. A total of 1051 differential proteins were screened by nano High Performance Liquid Chromatography - Mass Spectrometry / Mass Spectrometry (Nano HPLC-MS/MS). The top two proteins among different peritoneal transport characteristics were Orosomucoid 2 (ORM2) and C-reactive protein (CRP). To verify the above biomarkers, a larger population of PD patients were enrolled. Immunoturbidimetric assay showed that CRP was significantly elevated in $\mathrm{H}$ group than LA\&L group, consistent with the result of proteomic analysis. Western blot validated that ORM2 in serum was increased in LA\&L group compared with $\mathrm{H}$ and HA group. The expression of ORM2 in peritoneum also altered progressively in three groups. At last, supplying exogenous ORM could actually change peritoneal substances transport by reducing peritoneal proteins loss, without causing an excessive pro-inflammatory response in mice.

Conclusions: Serum ORM2 and CRP could be used as biomarkers to predict the baseline peritoneal transport characteristics, so as to guide the early PD treatment. ORM also raised the possibility of decreasing peritoneal proteins loss in PD patients.

\section{Background}

Peritoneal dialysis (PD) is an effective, convenient and safe treatment for end-stage renal disease (ESRD) patients. PD therapy implies a peritoneal catheter set in peritoneal cavity, with a long-term glucose dialysate exchange to eliminate toxins. Peritoneal equilibration test (PET) developed by Twardowski[1] divided the peritoneal transport characterics as low (L), low average (LA), high average $(H A)$, and high $(H)$. Patients with higher transport characteristics need shorter dialysate dwell times, and have poorer nutrition status and prognosis as a significant independent risk factor for death [2-4]. The Kidney Disease Outcomes Quality Initiative (KDOQI) guidelines suggest that the first PET should be performed 4-8 weeks after PD start. During this waiting period, the patients was given an empirical dialysis prescription due to unknown peritoneal transport characteristics. If we find biomarkers to predict the baseline peritoneal transport characteristics before PD commencement, we could give an accurate PD prescription as soon as PD start instead of waiting for 4-8 weeks.

The peritoneal transport characteristics change with dialysis vintage and peritonitis episodes after PD start[5]. However, before PD start, the baseline peritoneal transport characteristics also have great difference among ESRD patients, suggesting some factors affect the peritoneum earlier than the influence of glucose dialysate and inflammatory response. Previous studies found that racial origin, age, gender, BMI and complications such as hypertension, diabetes and malnutrition might influence baseline transport characteristics[6, 7]. Some cytokines like vascular endothelial growth factor and interleukin-6 might also be correlated with the peritoneal transport characteristics[8, 9]. However, they were not sufficient to predict baseline transport status and enter clinical practice with systematical validation.

Proteomic technologies have been widely used for discovering unknown proteins and generating new hypotheses. Nano High Performance Liquid Chromatography - Mass Spectrometry / Mass Spectrometry (Nano HPLC-MS/MS) is a superior platform for protein identification, which is more sensitive and reliable compared to conventional technology[10]. In this study, we used Nano HPLC-MS/MS analysis to identify serum biomarkers which can predict baseline peritoneal transport characteristics in PD patients. Orosomucoid 2 (ORM2) and C-reactive protein (CRP) were selected for further validation by western blot, immunoturbidimetric assay and immunohistochemistry staining. Additionally, the role of ORM in regulating transport function was further analyzed in mice. 
To the best of our knowledge, this was the first study to use proteomic analysis to predict the baseline peritoneal transport characteristics from blood sample of ESRD patients. We also described the role of ORM in altering peritoneal substances transport.

\section{Materials And Methods Study design}

We enrolled 245 incident PD patients using glucose dialysate (Dianeal, Baxter) in our center from May 2016 to December 2019. Exclusion criteria were acute kidney injury cause; PD-associated peritonitis or receiving hemodialysis before the first PET; history of abdominal surgery; acute cardiovascular events occurred within 3 months before PD; malignant tumor; corticosteroids or immunosuppressive agents used within 1 year before PD. Acute cardiovascular events include acute myocardial infarction, angina, pulmonary embolism and aortic dissection. As a part of the regular medical care, all patients required standard PET to assess their baseline peritoneal transport characteristics and dialysis adequacy 4-8 weeks after PD start. This study was approved by the Ethical Committee, Zhongshan Hospital, Fudan University, and all participants provided written informed consent.

The overall study flow was summarized in Fig. 1. For the discovery phase, 58 PD patients and 21 normal controls (NC) were enrolled to proteomic analysis. For further validation of the marker candidates, 187 PD patients and 25 NC were enrolled. Western blot and immunohistochemical staining were used to verify ORM2 in serum or peritoneum. Immunoturbidimetric assay was performed to measure serum CRP. At last, we investigated the function of ORM in altering peritoneal transport of substances in mice.

\section{Peritoneal equilibration test in PD patients}

Peritoneal transport characteristics were assessed by standard PET as described previously[11]. Briefly, a standard 4-hour dwell time was performed with 2 liters $2.5 \%$ glucose dialysate. The results were calculated by using PD Adequest software (Baxter Healthcare Corporation, Chicago, IL, USA). Peritoneal transport characteristics were categorized as high (H), high average $(H A)$, low average $(L A)$ and low $(L)$ transport characteristics, according to dialysate-to-plasma ratio of creatinine (D/Pcr) $4 \mathrm{~h}$ values ( $\mathrm{L}<0.50$, LA 0.5-0.65, HA 0.66-0.80, H>0.80). L were combined into LA (LA\&L) in our study due to relatively few patients.

\section{Nano-HPLC-MS/MS, pathway and network analyses}

$5 \mathrm{ml}$ blood samples were collected within 3 days before PD start in a discovery set. After centrifugation (3000 g for $10 \mathrm{~min}$ ), the serum was immediately frozen at $-80^{\circ} \mathrm{C}$ until use. After knowing the PET results, the serum samples were divided into $\mathrm{H}$, HA or LA\&L group. $10 \mu$ of each serum sample in H, HA or LA\&L group were pooled, respectively. Nano-HPLC-MS/MS analysis was employed to identify serum biomarkers. The detailed method was performed as we described previously[12]. The proteome profiles were clustered based on Euclidean distances with average linkage using modified function Clutergram in MATLAB R2014b.

\section{Validation based on western blot analysis}

The expression of serum ORM2 was detected by western blot to confirm the results of proteomics study, using serum within 3 days before PD start in a validation set. For each sample, $0.4 \mu \mathrm{l}$ serum was diluted with $2.8 \mu$ phosphate buffer saline, then added $0.8 \mu$ l loading buffer ( $5 \times$ ). The samples were separated by electrophoresis, transferred onto a PVDF membrane (Sigma), incubated with primary anti-ORM2 antibody (Abcam, ab231906, 1:5000), and finally incubated with corresponding secondary antibody. The result was quantified by using Image $\mathrm{J}$ and the Coomassie brilliant blue staining was used as the loading control.

Peritoneum tissue collection and immunohistochemistry 
To explore the expression of the biomarker in peritoneum, parietal peritoneum (approximately $0.5 \mathrm{~cm}^{2}$ ) was taken during the peritoneal catheter placement surgery in PD patients, or during hernia repair surgery in NC. The peritoneum was fixed in $4 \%$ paraformaldehyde overnight, followed by routine paraffin embedding, and sliced into $3 \mu \mathrm{m}$ sections. After being dewaxed and hydrated, primary antibody ORM2 (1:100) was incubated overnight. After washing, the corresponding secondary antibody was incubated. DAB was added to develop color. The tissue was finally observed under a microscope (400x).

\section{Peritoneal equilibration test in mice}

Male, 6-8 week-old C57BL/6 J mice were used, which were similar in terms of body weight and body surface area. The ORM (Sigma) was purified from human plasma, containing both ORM1 and ORM2. Animals were randomized into three groups: control group $(n=6)$; PET group $(n=6) ;$ PET + ORM group $(n=6)$. At $0 h$, control mice and PET mice were intraperitoneal injected (i.p.) $0.9 \% \mathrm{NaCl} 100 \mu \mathrm{l}$, while PET + ORM group were received ORM $30 \mathrm{mg} / \mathrm{kg} 100 \mu \mathrm{l}$ i.p. After 2 hours, PET group and PET + ORM group were submitted to a 2-hour PET to measure solute transport parameters by giving $2 \mathrm{ml} 4.25 \%$ glucose dialysate (Dianeal, Baxter) i.p. At the end, the mice were anesthetized and sacrificed. Meanwhile, blood, peritoneal dialysis effluents (PDE) and peritoneum were collected. Urea, total proteins and albumin were measured by full automatic biochemical instrument in Zhongshan Hospital. PDE volume was measured with a precision pipette. All the experimental procedures in this study were approved by the Animal Experimentation Ethics Committee of Fudan University, Zhongshan Hospital.

\section{Real-time quantitative PCR}

Total RNA was extracted from mice parietal peritoneum using Trizol reagent (Sigma). Total RNA (500 ng) was used for realtime quantitative PCR with PrimeScript RT Master Mix Kit (TaKaRa) and SYBR Premix Ex Taq Kit (TaKaRa). 2- $\Delta \Delta$ Ct method was used to calculate relative mRNA expression. Expression levels were normalized to the control gene $\beta$-actin. The primers were listed in Additional file 1: Table S1.

\section{Statistical analysis}

All data were presented as mean \pm SD or median (interquartile range) or number (\%). The statistical analysis was performed using SPSS (version 23.0) and GraphPad Prism (version 7.0). For continuous measurements, Student's t test or one-way ANOVA with Bonferroni corrections was adopted. For categorical data, chi-square was used within group comparisons. A $P$ value $<0.05$ was considered statistically significant.

\section{Results}

\section{Basic demographic and clinical characteristics of patients with different peritoneal transport characteristics}

The PD patients were grouped as H, HA and LA\&L according to the standard PET. The basic data were collected before PD start as shown in Table 1. No significant differences were found in the age, gender, estimated Glomerular Filtration Rate (eGFR), body surface area, blood pressure, diabetes mellitus ratio, blood urea nitrogen, serum creatinine, hemoglobin and prealbumin. However, albumin decreased in $\mathrm{H}$ group compared to LA\&L group in a validation set $(P<0.05)$. 
Table 1

Statistics of the basic data collected from the patients

\begin{tabular}{|c|c|c|c|c|c|c|c|c|}
\hline \multirow[t]{2}{*}{ Clinical indices } & \multicolumn{3}{|c|}{ Discovery $(n=58)$} & \multirow{2}{*}{$\begin{array}{l}P \\
\text { value }\end{array}$} & \multicolumn{3}{|c|}{ Validation $(n=187)$} & \multirow{2}{*}{$\begin{array}{l}P \\
\text { value }\end{array}$} \\
\hline & $H(n=17)$ & $\begin{array}{l}\mathrm{HA} \\
22)\end{array}(n=$ & $\begin{array}{l}\text { LA\&L }(n \\
=19)\end{array}$ & & $H(n=41)$ & $\begin{array}{l}\mathrm{HA}(\mathrm{n}= \\
72)\end{array}$ & $\begin{array}{l}\text { LA\&L }(n= \\
74)\end{array}$ & \\
\hline Age (year) & $\begin{array}{l}60.18 \pm \\
18.12\end{array}$ & $\begin{array}{l}52.50 \pm \\
15.48\end{array}$ & $\begin{array}{l}47.21 \pm \\
13.91\end{array}$ & 0.056 & $\begin{array}{l}63.05 \pm \\
14.38\end{array}$ & $\begin{array}{l}58.18 \pm \\
15.15\end{array}$ & $\begin{array}{l}56.07 \pm \\
16.58\end{array}$ & 0.072 \\
\hline Male gender (\%) & $12(70.6 \%)$ & $16(72.7 \%)$ & $8(42.1 \%)$ & 0.091 & $23(56.1 \%)$ & $44(61.1 \%)$ & $33(44.6 \%)$ & 0.126 \\
\hline $\begin{array}{l}\text { eGFR } \\
\left(\mathrm{mL} / \mathrm{min} / 1.73 \mathrm{~m}^{2}\right)\end{array}$ & $\begin{array}{l}5.72 \pm \\
1.91\end{array}$ & $\begin{array}{l}5.28 \pm \\
1.86\end{array}$ & $\begin{array}{l}4.83 \pm \\
1.19\end{array}$ & 0.293 & $\begin{array}{l}6.00 \pm \\
1.89\end{array}$ & $\begin{array}{l}5.73 \pm \\
1.95\end{array}$ & $\begin{array}{l}5.89 \pm \\
1.98\end{array}$ & 0.761 \\
\hline $\operatorname{BSA}\left(m^{2}\right)$ & $\begin{array}{l}1.74 \pm \\
0.16\end{array}$ & $\begin{array}{l}1.73 \pm \\
0.18\end{array}$ & $\begin{array}{l}1.61 \pm \\
0.18\end{array}$ & 0.053 & $\begin{array}{l}1.71 \pm \\
0.21\end{array}$ & $\begin{array}{l}1.75 \pm \\
0.22\end{array}$ & $\begin{array}{l}1.71 \pm \\
0.21\end{array}$ & 0.370 \\
\hline $\mathrm{SBP}(\mathrm{mmHg})$ & $\begin{array}{l}145.98 \pm \\
18.96\end{array}$ & $\begin{array}{l}150.73 \pm \\
15.05\end{array}$ & $\begin{array}{l}148.45 \\
\pm 19.27\end{array}$ & 0.708 & $\begin{array}{l}144.83 \pm \\
18.89\end{array}$ & $\begin{array}{l}144.44 \pm \\
22.73\end{array}$ & $\begin{array}{l}140.97 \pm \\
15.50\end{array}$ & 0.477 \\
\hline $\mathrm{DBP}(\mathrm{mmHg})$ & $\begin{array}{l}79.89 \pm \\
10.95\end{array}$ & $\begin{array}{l}84.79 \pm \\
11.04\end{array}$ & $\begin{array}{l}86.26 \pm \\
10.57\end{array}$ & 0.196 & $\begin{array}{l}82.46 \pm \\
12.90\end{array}$ & $\begin{array}{l}80.35 \pm \\
11.47\end{array}$ & $\begin{array}{l}82.55 \pm \\
11.56\end{array}$ & 0.537 \\
\hline DM ratio (\%) & $5(29.4 \%)$ & $6(27.3 \%)$ & $3(15.8 \%)$ & 0.577 & $9(22.0 \%)$ & $16(22.2 \%)$ & $14(18.9 \%)$ & 0.870 \\
\hline BUN (mmol/L) & $\begin{array}{l}27.96 \pm \\
7.46\end{array}$ & $\begin{array}{l}30.41 \pm \\
5.29\end{array}$ & $\begin{array}{l}27.76 \pm \\
6.39\end{array}$ & 0.337 & $\begin{array}{l}26.49 \pm \\
8.80\end{array}$ & $\begin{array}{l}25.54 \pm \\
9.58\end{array}$ & $\begin{array}{l}24.69 \pm \\
7.93\end{array}$ & 0.571 \\
\hline $\mathrm{SCr}(\mu \mathrm{mol} / \mathrm{L})$ & $\begin{array}{l}726(596 \\
1012)\end{array}$ & $\begin{array}{l}812(669 \\
1176)\end{array}$ & $\begin{array}{l}817(738 \\
1012)\end{array}$ & 0.253 & $\begin{array}{l}725.49 \pm \\
181.36\end{array}$ & $\begin{array}{l}810.08 \pm \\
265.97\end{array}$ & $\begin{array}{l}759.57 \pm \\
236.57\end{array}$ & 0.167 \\
\hline Hemoglobin $(\mathrm{g} / \mathrm{L})$ & $\begin{array}{l}89.9 \pm \\
16.6\end{array}$ & $\begin{array}{l}85.5 \pm \\
18.1\end{array}$ & $\begin{array}{l}87.8 \pm \\
17.2\end{array}$ & 0.718 & $\begin{array}{l}91.22 \pm \\
13.86\end{array}$ & $\begin{array}{l}89.56 \pm \\
15.83\end{array}$ & $\begin{array}{l}94.91 \pm \\
19.31\end{array}$ & 0.155 \\
\hline $\begin{array}{l}\text { Serum albumin } \\
(\mathrm{g} / \mathrm{L})\end{array}$ & $34.6 \pm 5.7$ & $36.4 \pm 6.0$ & $\begin{array}{l}37.3 \pm \\
4.2\end{array}$ & 0.331 & $\begin{array}{l}34.78 \pm \\
4.63\end{array}$ & $\begin{array}{l}35.01 \pm \\
4.83\end{array}$ & $\begin{array}{l}36.62 \pm \\
3.89^{\square}\end{array}$ & $\begin{array}{l}< \\
0.05\end{array}$ \\
\hline $\begin{array}{l}\text { Serum } \\
\text { prealbumin }(\mathrm{mg} / \mathrm{L})\end{array}$ & $\begin{array}{l}0.33 \pm \\
0.07\end{array}$ & $\begin{array}{l}0.34 \pm \\
0.08\end{array}$ & $\begin{array}{l}0.36 \pm \\
0.07\end{array}$ & 0.343 & $\begin{array}{l}0.31 \pm \\
0.06\end{array}$ & $\begin{array}{l}0.31 \pm \\
0.06\end{array}$ & $\begin{array}{l}0.33 \pm \\
0.06\end{array}$ & 0.248 \\
\hline \multicolumn{9}{|c|}{$\begin{array}{l}\text { eGFR, estimated Glomerular Filtration Rate; BSA, body surface area; SBP, systolic blood pressure; DBP, diastolic blood } \\
\text { pressure; DM, diabetes mellitus; BUN, blood urea nitrogen; SCr, serum creatinine; H, high transport characteristics; HA, high } \\
\text { average transport characteristics; LA\&L, low average and low transport characteristics. Data were presented as mean } \pm\end{array}$} \\
\hline
\end{tabular}

Nano-HPLC-MS/MS quantification of differentially expressed proteins in patients with different peritoneal transport properties and for pathway and network analyses

Serum samples from H, HA, LA\&L and NC groups were analyzed by nano LC-MS/MS. In total, 1051 proteins were identified. Ratio $>1.3$ means up-regulation, and Ratio $<0.77$ means down-regulation. Among these proteins, several proteins were upregulated or down-regulated in different groups as shown in Table 2. Compared to NC, there were 30 simultaneously upregulated proteins and 7 simultaneously down-regulated proteins among all three transporters (Fig. 2). 
The up-regulated proteins and down-regulated proteins in H, HA, LA\&L group when compared with NC.

\begin{tabular}{|llll|}
\hline & up-regulated & down-regulated & total \\
\hline H.vs.NC & 54 & 22 & 76 \\
\hline HA.vs.NC & 65 & 26 & 43 \\
\hline L\&LA.vs.NC & 35 & 8 & \\
\hline $\begin{array}{l}\text { Ratio > 1.3 means up-regulation, and Ratio < 0.77 means down-regulation. H, high transport characteristics; HA, high } \\
\text { average transport characteristics; LA\&L, low average and low transport characteristics; NC, negative control. }\end{array}$ \\
\hline
\end{tabular}

Gene Ontology (GO) analysis showed that compared with NC, proteins involved in inflammatory response and immune system process were all enriched in H, HA and LA\&L groups (Fig. 3).

To explore the different expression trend of these proteins in different PD transporters, K-means clustering analysis were performed. The 1051 proteins were classified into 16 clusters by the K-means clustering algorithm, and five of the top ranked proteins, which were progressively up-regulated or down-regulated among different transporters were shown in Table 3.

Table 3

Top five differential proteins between different PD transporters

\begin{tabular}{|lllllll|}
\hline No. & Gene name & Protein name & cluster & H:NC & HA:NC & LA\&L:NC \\
\hline 1 & ORM2 & Alpha-1-acid glycoprotein 2 & 1 & 1.33 & 1.56 & 3.23 \\
\hline 2 & CRP & C-reactive protein & 12 & 3.33 & 2.54 & 2.11 \\
\hline 3 & NCOA1 & Nuclear receptor coactivator 1 & 1 & 1.19 & 0.83 & 3.22 \\
\hline 4 & E9PFG7 & 2-oxoglutarate dehydrogenase mitochondrial & 5 & 3.13 & 1.49 & 1.06 \\
\hline 5 & TUBA4A & Tubulin alpha-4A chain & 9 & 0.27 & 0.37 & 1.44 \\
\hline $\begin{array}{l}\text { H, high transport characteristics; HA, high average transport characteristics; LA\&L, low average and low transport } \\
\text { characteristics; NC, negative control. }\end{array}$ & & & & \\
\hline
\end{tabular}

\section{Validation of ORM2 and CRP}

Top two ranked proteins (ORM2 and CRP) were chosen for further validation. We first conducted Western blot analysis with a validation set of serum samples to identify ORM2. Serum ORM2 of LA\&L group were significantly higher than H, HA and NC group (Fig. 4a and 4b, all $P<0.05$ ). Immunoturbidimetric assay showed that there was significant difference of CRP between four groups $(P<0.01)$ (Fig. 4C). Furthermore, CRP in H group was increased compared with LA\&L group $(P<0.05)$ and NC group $(P<0.01)$. These results were almost consistent with the proteomic analysis.

\section{The expression of ORM2 in peritoneum}

To investigate whether ORM2 was involved in peritoneal transport, we used immunohistochemical staining to observe the expression of ORM2 in peritoneum of incident PD patients. It showed that ORM2 was positively expressed in cytoplasm of human peritoneal mesothelial cells (HPMCs) and peritoneal vascular endothelial cells (PVECs). The expression of ORM2 was gradually increased in H, HA and LA\&L groups in HPMCs and PVECs (Fig. 5). These results suggested that ORM2 was not only a serum marker to predict peritoneal transport characteristics, but also may be directly involved in peritoneal substances transport in PD patients.

\section{Peritoneal equilibration test in mice}


In order to further verify whether ORM2 directly participated in altering peritoneal substances transport, we performed $2 \mathrm{~h}$ PET in mice to investigate the role of ORM. There was no significant difference of net ultrafiltration / body weight between PET and PET + ORM groups (Fig. 6a). Since the serum creatinine of non-uremic mice is low (about $0.4 \mathrm{mg} / \mathrm{dl}$ ), and low dialysate creatinine concentration combined with high dialysate glucose interference results in a large error, so we used the dialysateto-plasma (D/P) ratio of urea to access small molecules transport. There was a trend toward lower D/P urea in PET + ORM group as compared with PET group, but the difference was not significant (Fig. 6b). Proteins are large, negatively charged molecules. Dialysate total proteins $(P<0.05)$ and dialysate albumin $(P<0.05)$ of PET + ORM group was significantly lower than ORM group (Fig. $6 \mathrm{c}$ and $6 \mathrm{~d}$ ). These results indicated that supplying exogenous ORM could reduce dialysate total proteins and albumin loss.

\section{Discussion}

The classification of peritoneal transport characteristics is primarily measured 4-8 weeks after PD start by PET. This proteomic study focused on developing new and better biomarkers to distinguish the transport characteristics directly before PD start. This research identified and verified two proteins, ORM2 and CRP, as biomarkers to predict the baseline peritoneal transport characteristics.

ORM, also known as AGP (alpha-1-acid glycoprotein), mainly including ORM1 and ORM2, belongs to acute-phase protein family and is heavily glycosylated (45\%)[13]. ORM is almost synthesized in the liver, and it can also be produced by endothelial cells, then released into the circulation[14]. Increased ORM expression has been associated with acute infection, chronic diseases, and different kinds of cancers $[15,16]$. Previous research showed that serum ORM was higher in ESRD patients before PD start compared with healthy controls in small series[17], but they do not classify different peritoneal transport characteristics. In this study, the result of western blot showed that ORM2 in LA\&L group was higher than H, HA and NC group, clearly confirmed our proteomic data. Therefore, LA\&L group could be distinguished from H, HA group by increased serum ORM2 level.

We also validated that elevated serum ORM2 was associated with its increased expression in peritoneum, suggesting ORM2 was directly involved in peritoneal transport. Peritoneum has size barriers and charge barriers, which affected the ability of a molecule to permeate the peritoneum[18, 19]. ORM is the negatively charged plasma protein, due to the high level of sialic acid content at the terminal of glycan chains $[13,20]$. The isoelectric point (pl) value of ORM is $2.7-3.2$, while the pl value of CRP is 7.9-9.0[21, 22]. ORM has been reported to increase the polyanionic charge selectivity, inhibit the trans-vascular leakage of negatively charged substances like proteins or albumin[23], and protect vascular permeability in endothelial barrier[14] and blood-brain barrier by increasing tight junction protein (occludin and zonula occludens-1) expression[24, 25]. It also can suppress the renal filtration of albumin as the major components of the glomerular endothelial cell coat[26]. In our study, we found that peritoneal total proteins and albumin loss were reduced after giving exogenous ORM2 to mice. Due to the negative charge effect of ORM2 as known, we thought that local high expression of ORM or giving exogenous ORM may add more negative charge to the surface of cell, thus reduce the loss of negatively charged proteins or albumin into the PDE (Fig. 7). Therefore, it may explain why the patients in LA\&L group with higher serum ORM2 had higher serum albumin than $\mathrm{H}$ group. Previous study also showed that higher baseline peritoneal transport characteristics were associated with lower serum albumin[27]. Peritoneal albumin loss was one of the causes of hypoalbuminemia in PD patients[28], which was also related to malnutrition, increased plasma viscosity, carotid atherosclerotic plaques and cardiovascular events[29, 30]. These results

indicated that supplying exogenous ORM in PD patients is likely to have a protective effect by preventing hypoalbuminemia caused by high peritoneal transport.

Creatinine and urea are both small molecule toxins which can be partly eliminated by PD therapy. D/P urea is correlated positively with D/P creatinine[19]. The $2 \mathrm{~h}$ PET result in mice showed that there was no significant difference of D/P urea between PET and PET + ORM groups. It suggested that giving $30 \mathrm{mg} / \mathrm{kg}$ ORM to mice as an appropriate concentration did not influence the elimination of small molecule toxins. 
Higher peritoneal transport characteristics was reportedly associated with intraperitoneal inflammation, which was largely independent of systemic inflammation[31,32]. ORM has both pro-inflammatory and anti-inflammatory roles in different diseases[25, 33, 34]. Whether ORM can stimulate HPMCs and PVECs to express pro-inflammatory or anti-inflammatory cytokines remains unknown. Thus, we measured the mRNA level of cytokines in mice peritoneum to exclude the influence of local inflammation. PET with or without ORM neither increased the expression of IL-6, TNF- $a$ and IL-10 in peritoneum (Additional file 2: Figure S1), suggesting that the mice did not have peritonitis, and ORM was safe and effective in reducing proteins loss without causing an excessive pro-inflammatory response.

Increased serum CRP is associated with inflammation, peritoneal fibrosis, cardiovascular morbidity and overall mortality[35, 36]. CRP-transgenic mice had higher D/P creatinine ratio than that of WT mice[35]. A cross-sectional study showed that CRP in $\mathrm{H}$ and HA group was higher than LA and L group[37], and CRP has been verified to be able to distinguish different transport status in long dialysis vintage PD patients[38]. We found that $\mathrm{H}$ group also had higher serum $\mathrm{CRP}$ concentration compared with LA\&L group or NC group, which means CRP may have the capacity to discriminate the $\mathrm{H}$ transport characteristic from LA\&L transport characteristic in incident PD patients, too. Additionally, a collection of biomarkers, ORM2 and CRP, can outperform a single biomarker to discriminate different peritoneal transport characteristics.

The limitations of this study were that the sample size was small; the function of ORM was based on experiment in nonuremic animals; the result could only predict the baseline peritoneal transport characteristics. Peritoneal transport characteristics change over time[5], and the serum ORM2 and CRP may be influenced by dialysis vintage. Future studies should focus on the quantitative investigation of ORM2 in larger PD patient cohorts to provide robust validation, and the mechanism associated with ORM and peritoneal transport characteristics by assessing the charge on the human peritoneum.

\section{Conclusions}

In this study, we identified and validated ORM2 and CRP as potential biomarkers to predict baseline peritoneal transport characteristics. Increased ORM2 suggested lower peritoneal transport characteristics, while increased CRP suggested higher peritoneal transport characteristics. We also revealed that the ORM role of decreasing proteins loss, which might have clinical value in decreasing peritoneal proteins loss and preventing hypoalbuminemia in PD patients.

\section{Abbreviations}

PD: peritoneal dialysis; ESRD:end-stage renal disease; PET:peritoneal equilibration test; ORM:Orosomucoid; CRP:C-reactive protein; nano HPLC-MS/MS:nano High Performance Liquid Chromatography - Mass Spectrometry / Mass Spectrometry; HPMCs:human peritoneal mesothelial cells; PVECs:peritoneal vascular endothelial cells; KDOQI:Kidney Disease Outcomes Quality Initiative; H:high; HA:high average; LA:low average; L:Iow; NC:normal control.

\section{Declarations}

\section{Authors' contributions}

MB completed the experiments of the study and performed the statistical analysis. ZS and XY participated in its design and coordination. JJ, LZ and BX participated in clinical sample and data collection. GY guided the proteomic analysis. XD, JZ and $X Y$ gave a valuable guidance in manuscript writing. All authors read and approved the final manuscript.

\section{Author details}

${ }^{1}$ Division of Nephrology, Zhongshan Hospital, Fudan University, Shanghai 200032, China; ${ }^{2}$ Shanghai Institute of Kidney Disease and Dialysis, Shanghai 200032, China; ${ }^{3}$ Shanghai Key Laboratory of Kidney disease and Blood Purification, Shanghai 200032, China; ${ }^{4}$ Shanghai Medical Center of Kidney, Shanghai 200032, China; ${ }^{5}$ Key Laboratory of Metabolism and 
Molecular Medicine, Ministry of Education, and Department of Biochemistry and Molecular Biology, School of Basic Medical Sciences, and Institutes of Biomedical Sciences, Fudan University, Shanghai 200032, China.

\section{Acknowledgments}

We thank all of the doctors at Nephrology Department of Zhongshan Hospital in Shanghai, China for their work.

\section{Competing interests}

The authors declare that they have no competing interests.

\section{Availability of data and materials}

Please contact author for data requests.

\section{Consent for publication}

All participants gave their written informed consent.

\section{Ethics approval and consent to participate}

The study protocol was approved by the Human Research Ethics Committee of Zhongshan Hospital, Fudan University. Animal experiments were approved by the Animal Experimentation Ethics Committee of Fudan University, Zhongshan Hospital.

\section{Funding}

This work was funded by the National Natural Science Foundation of China (81970667) and the Development Plan of Top Young Talents in Shanghai (2018).

\section{References}

1. Twardowski ZJ, Nolph KD, Khanna R, Prowant BF, Ryan LP, Moore HL, Nielsen MP: Peritoneal equilibration test. Peritoneal Dialysis Bulletin 1987, 7:138-147.

2. Harty J, Gokal R: The impact of peritoneal permeability and residual renal function on PD prescription. Perit Dial Int 1996, 16 Suppl 1:S147-152.

3. Mujais S, Vonesh E: Profiling of peritoneal ultrafiltration. Kidney Int Supp/ 2002:S17-22.

4. Guan JC, Bian W, Zhang XH, Shou ZF, Chen JH: Influence of peritoneal transport characteristics on nutritional status and clinical outcome in Chinese diabetic nephropathy patients on peritoneal dialysis. Chin Med J (Engl) 2015, 128:859-864.

5. Davies SJ: Longitudinal relationship between solute transport and ultrafiltration capacity in peritoneal dialysis patients. Kidney Int 2004, 66:2437-2445.

6. Cueto-Manzano AM: Rapid solute transport in the peritoneum: physiologic and clinical consequences. Perit Dial Int 2009, 29 Suppl 2:S90-95.

7. Rumpsfeld M, McDonald SP, Purdie DM, Collins J, Johnson DW: Predictors of baseline peritoneal transport status in Australian and New Zealand peritoneal dialysis patients. Am J Kidney Dis 2004, 43:492-501.

8. Miyata T, Devuyst O, Kurokawa K, van Ypersele de Strihou C: Toward better dialysis compatibility: advances in the biochemistry and pathophysiology of the peritoneal membranes. Kidney Int 2002, 61:375-386.

9. Gillerot G, Goffin E, Michel C, Evenepoel P, Biesen WV, Tintillier M, Stenvinkel P, Heimbürger O, Lindholm B, Nordfors L, et al: Genetic and clinical factors influence the baseline permeability of the peritoneal membrane. Kidney Int 2005, 67:24772487. 
10. Altomare A, Fasoli E, Colzani M, Paredes Parra XM, Ferrari M, Cilurzo F, Rumio C, Cannizzaro L, Carini M, Righetti PG, Aldini G: An in depth proteomic analysis based on ProteoMiner, affinity chromatography and nano-HPLC-MS/MS to explain the potential health benefits of bovine colostrum. J Pharm Biomed Anal 2016, 121:297-306.

11. Twardowski ZJ: Clinical value of standardized equilibration tests in CAPD patients. Blood Purif 1989, 7:95-108.

12. Yu X, Cai J, Jiao X, Zhang S, Liu H, Ding X: Response Predictors to Calcineurin Inhibitors in Patients with Primary Membranous Nephropathy. Am J Nephro/ 2018, 47:266-274.

13. Hochepied T, Berger FG, Baumann H, Libert C: Alpha(1)-acid glycoprotein: an acute phase protein with inflammatory and immunomodulating properties. Cytokine Growth Factor Rev 2003, 14:25-34.

14. Sörensson J, Matejka GL, Ohlson M, Haraldsson B: Human endothelial cells produce orosomucoid, an important component of the capillary barrier. Am J Physiol 1999, 276:H530-534.

15. Gao F, Zhang X, Whang S, Zheng C: Prognostic impact of plasma ORM2 levels in patients with stage II colorectal cancer. Ann Clin Lab Sci 2014, 44:388-393.

16. Zhou Q, Andersson R, Hu D, Bauden M, Sasor A, Bygott T, Pawłowski K, Pla I, Marko-Varga G, Ansari D: Alpha-1-acid glycoprotein 1 is upregulated in pancreatic ductal adenocarcinoma and confers a poor prognosis. Transl Res 2019, 212:67-79.

17. Fraeyman NH, Van de Velde EJ, Belpaire FM, Lameire NH: Glycan microheterogeneity of alpha 1-acid glycoprotein in sera and dialysates of patients on continuous ambulatory peritoneal dialysis. Clin Chim Acta 1989, 181:47-54.

18. Rippe B, Davies S: Permeability of peritoneal and glomerular capillaries: what are the differences according to pore theory? Perit Dial Int 2011, 31:249-258.

19. Asano M, Ishii T, Hirayama A, Mizuno M, Suzuki Y, Sakata F, Akiyama SI, Maruyama S, Soga T, Kinashi H, et al: Differences in peritoneal solute transport rates in peritoneal dialysis. Clin Exp Nephrol 2019, 23:122-134.

20. Fournier T, Medjoubi NN, Porquet D: Alpha-1-acid glycoprotein. Biochim Biophys Acta 2000, 1482:157-171.

21. Das T, Sen AK, Kempf T, Pramanik SR, Mandal C, Mandal C: Induction of glycosylation in human C-reactive protein under different pathological conditions. Biochem J 2003, 373:345-355.

22. Barrabés S, Sarrats A, Fort E, De Llorens R, Rudd PM, Peracaula R: Effect of sialic acid content on glycoprotein pl analyzed by two-dimensional electrophoresis. Electrophoresis 2010, 31:2903-2912.

23. Haraldsson B, Rippe B: Orosomucoid as one of the serum components contributing to normal capillary permselectivity in rat skeletal muscle. Acta Physiol Scand 1987, 129:127-135.

24. Yuan W, Li G, Zeng M, Fu BM: Modulation of the blood-brain barrier permeability by plasma glycoprotein orosomucoid. Microvasc Res 2010, 80:148-157.

25. Zhang S, Mark KS: a1-Acid glycoprotein induced effects in rat brain microvessel endothelial cells. Microvasc Res 2012, 84:161-168.

26. Haraldsson BS, Johnsson EK, Rippe B: Glomerular permselectivity is dependent on adequate serum concentrations of orosomucoid. Kidney Int 1992, 41:310-316.

27. Liu Y, Huang R, Guo Q, Yang Q, Yi C, Lin J, Yu X, Yang X: Baseline higher peritoneal transport had been associated with worse nutritional status of incident continuous ambulatory peritoneal dialysis patients in Southern China: a 1-year prospective study. Br J Nutr 2015, 114:398-405.

28. Yeun JY, Kaysen GA: Factors influencing serum albumin in dialysis patients. Am J Kidney Dis 1998, 32:S118-125.

29. Yu Z, Tan BK, Dainty S, Mattey DL, Davies SJ: Hypoalbuminaemia, systemic albumin leak and endothelial dysfunction in peritoneal dialysis patients. Nephrol Dial Transplant 2012, 27:4437-4445.

30. Heaf JG: Peritoneal transport: getting more complicated. Nephrol Dial Transplant 2012, 27:4248-4251.

31. Davies SJ: Peritoneal solute transport and inflammation. Am J Kidney Dis 2014, 64:978-986.

32. del Peso G, Fernández-Reyes MJ, Hevia C, Bajo MA, Castro MJ, Cirugeda A, Sánchez-Tomero JA, Selgas R: Factors influencing peritoneal transport parameters during the first year on peritoneal dialysis: peritonitis is the main factor. 
Nephrol Dial Transplant 2005, 20:1201-1206.

33. Pukhal'skii AL, Shmarina GV, Kalashnikova EA, Shiyan SD, Kokarovtseva SN, Pukhal'skaya DA, Bovin NV: Effect of semisynthetic analog of alpha(1)-acid glycoprotein on immunomodulatory and antiinflammatory activity of natural glycoprotein. Bull Exp Biol Med 2000, 129:480-483.

34. Kustán P, Szirmay B, Kőszegi T, Ludány A, Kovács GL, Miseta A, Mühl D, Németh B, Kiss I, Németh Á, et al: Monitoring urinary orosomucoid in patients undergoing cardiac surgery: A promising novel inflammatory marker. Clin Biochem 2017, 50:1002-1006.

35. Poon PY, Lan HY, Kwan BC, Huang XR, Chow KM, Szeto CC, Li PK: Peritoneal inflammation and fibrosis in C-reactive protein transgenic mice undergoing peritoneal dialysis solution treatment. Nephrology (Carlton) 2017, 22:125-132.

36. Pecoits-Filho R, Bárány P, Lindholm B, Heimbürger O, Stenvinkel P: Interleukin-6 is an independent predictor of mortality in patients starting dialysis treatment. Nephrol Dial Transplant 2002, 17:1684-1688.

37. Sezer S, Tutal E, Arat Z, Akçay A, Celik H, Ozdemir FN, Haberal M: Peritoneal transport status influence on atherosclerosis/inflammation in CAPD patients. J Ren Nutr 2005, 15:427-434.

38. Wen Q, Zhang L, Mao HP, Tang XQ, Rong R, Fan JJ, Yu XQ: Proteomic analysis in peritoneal dialysis patients with different peritoneal transport characteristics. Biochem Biophys Res Commun 2013, 438:473-478.

\section{Additional Files}

Additional file 1: Table S1. The primers for real-time PCR.

Additional file 2: Figure S1. PET with or without ORM did not influence the expression of cytokines in peritoneum. a The mRNA level of IL- $6 / \beta$-actin. $\mathbf{b}$ The mRNA level of TNF- $\alpha / \beta$-actin. $\mathbf{c}$ The mRNA level of IL-10/ $\beta$-actin.

\section{Figures}




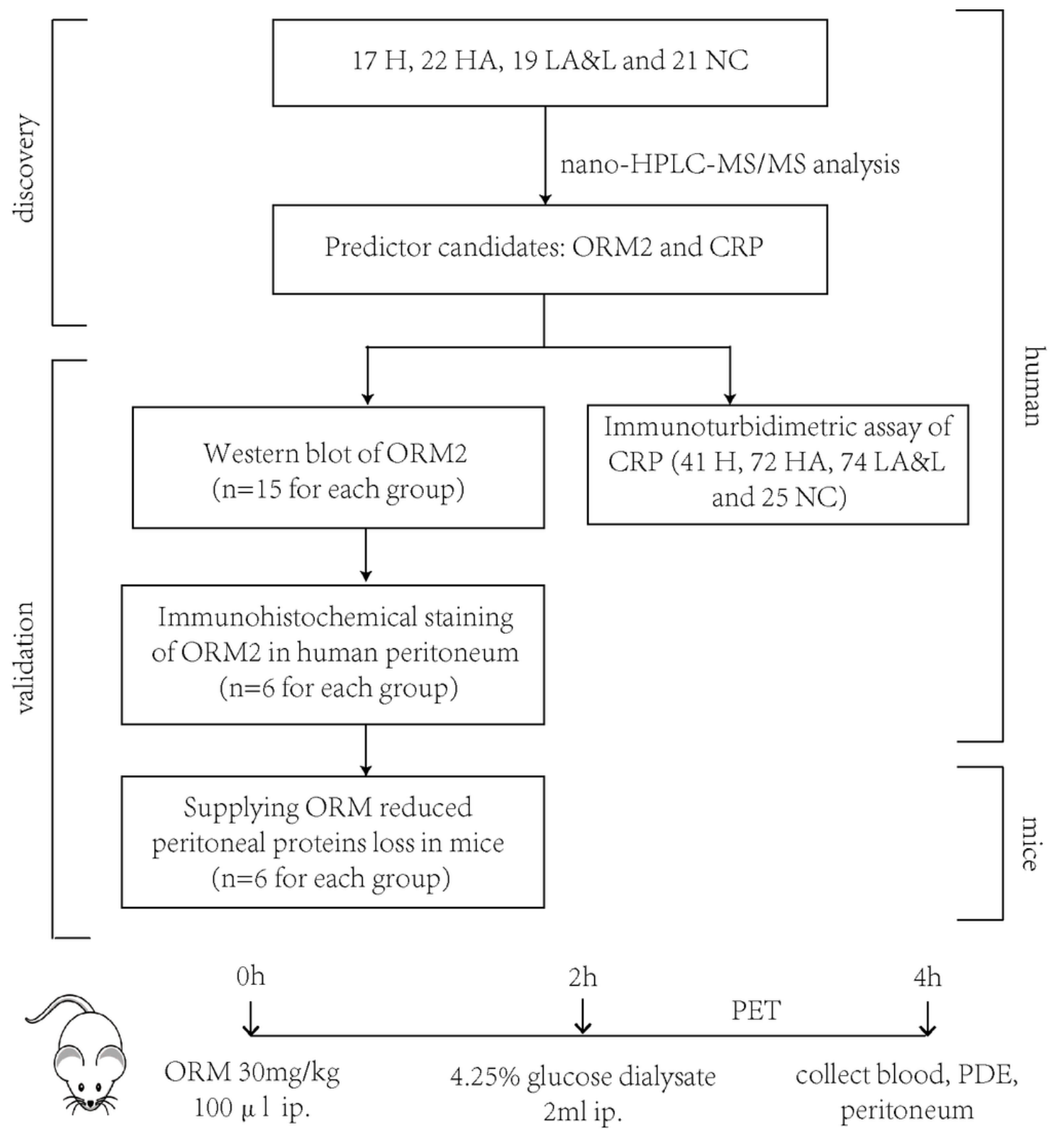

\section{Figure 1}

Study flow. $\mathrm{H}$, high transport characteristics; HA, high average transport characteristics; LA\&L, low average and low transport characteristics; NC, negative control; PDE, peritoneal dialysis effluents; PET, peritoneal equilibration test. 


\section{up-regulated proteins}

\section{down-regulated proteins}
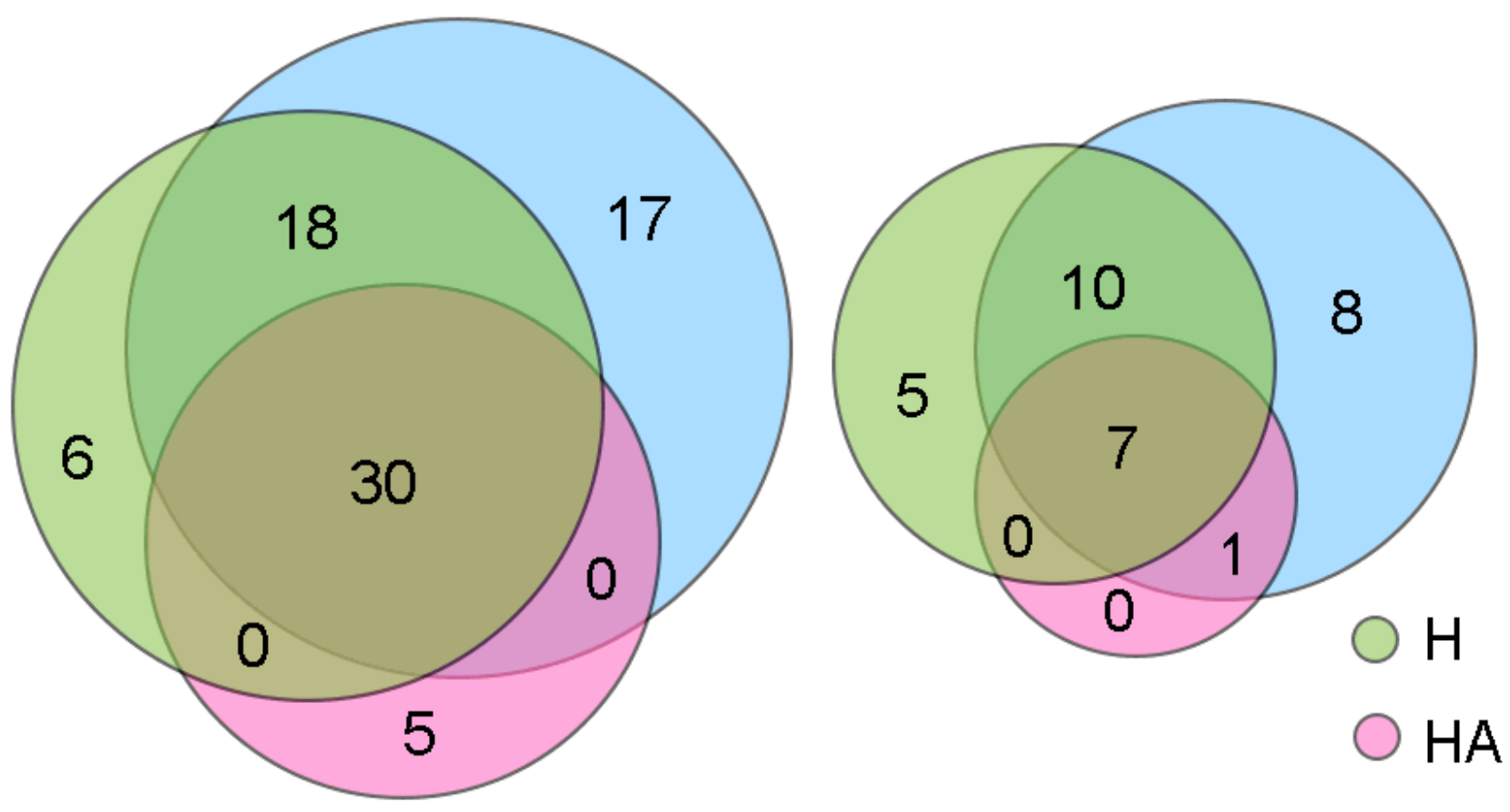

$\bigcirc$ LA\&L

\section{Figure 2}

Proteins differentially expressed in H, HA, LA\&L group when compared with NC. Compared with NC, 30 proteins were upregulated and 7 proteins were down-regulated simultaneously in all the PD patients. 

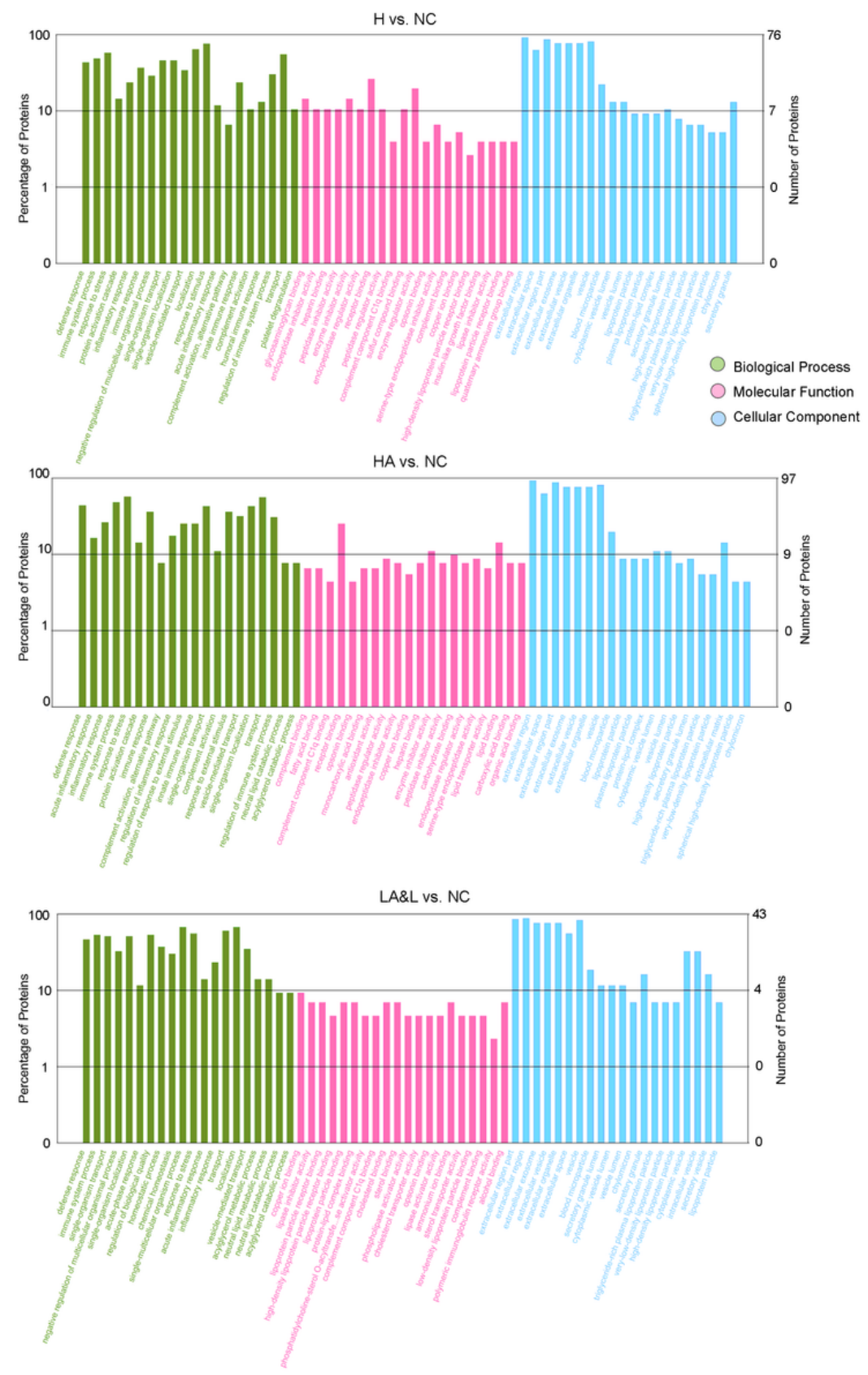

Figure 3

GO analysis between different PD transporter characteristics and NC. 
a

a H HA LA\&L NC

ORM2

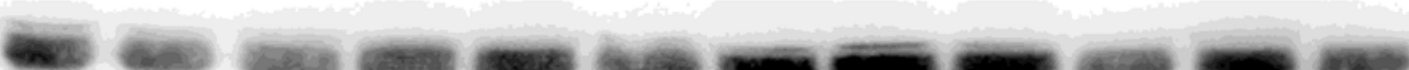
政

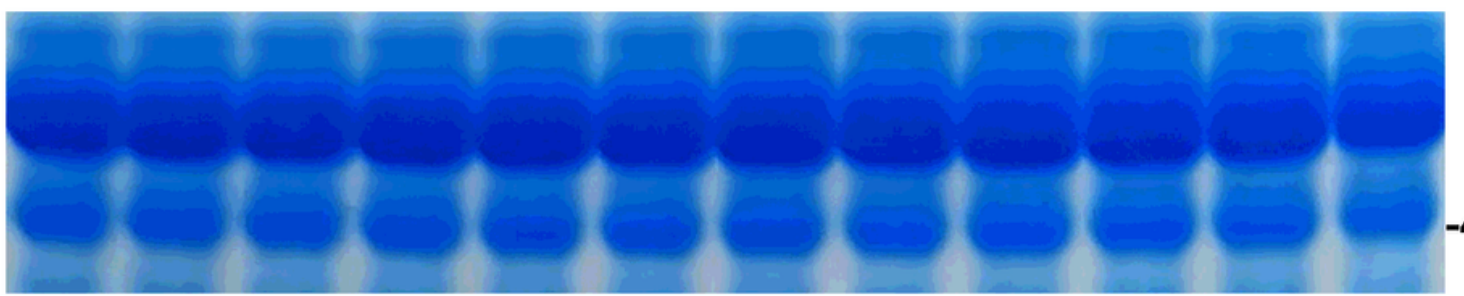

-45 kDa

$-45 \mathrm{kDa}$
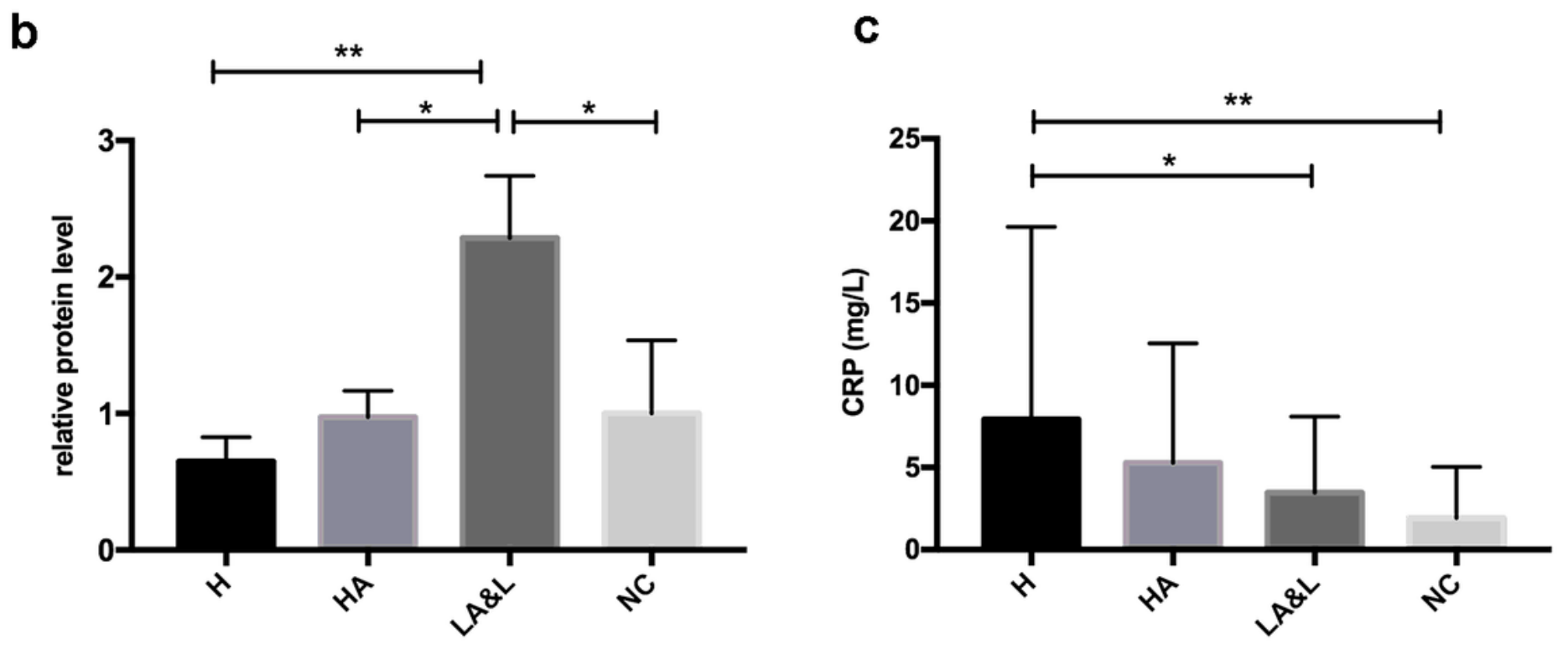

Figure 4

Western blot and Immunoturbidimetric assay of ORM2 and CRP. a Western blot validated the up-regulation of serum ORM2 in LA\&L group. The Coomassie brilliant blue staining (below) is the loading control. b Expression relative quantification of ORM2. c Immunoturbidimetric assay of CRP. खP $<0.05 \otimes \square \otimes P<0.01$ 

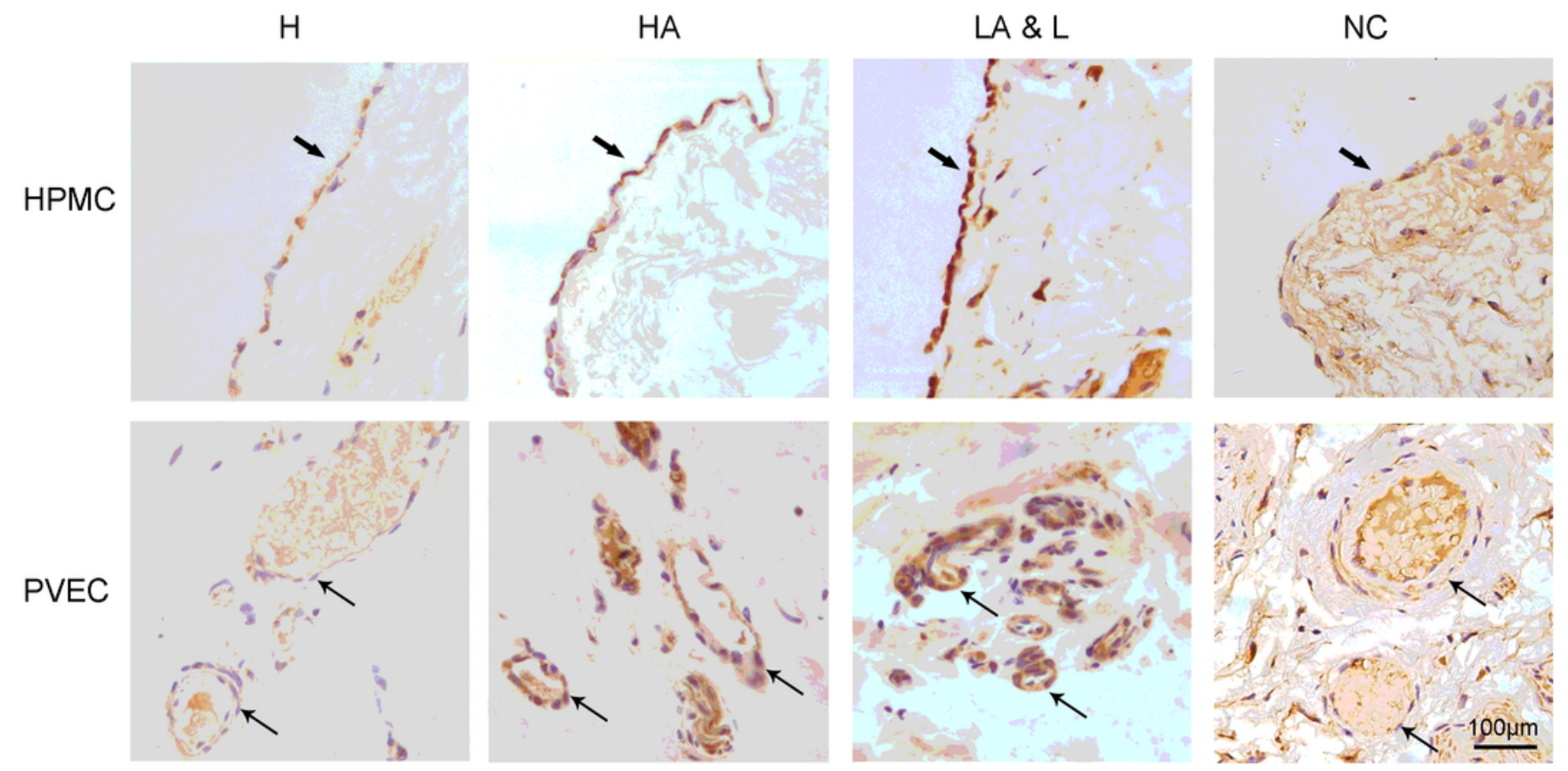

\section{Figure 5}

Representative immunohistochemical staining of ORM2 in the human parietal peritoneum ( $\mathrm{n}=6$ for each group). Increased cytoplasm staining was seen in peritoneum of PD patients among H, HA and LA\&L group, indicating increased expression of ORM2. Scale bar $=100 \mu \mathrm{m}$. Thick black arrows point to HPMC, and thin black arrows point to PVEC. 
a

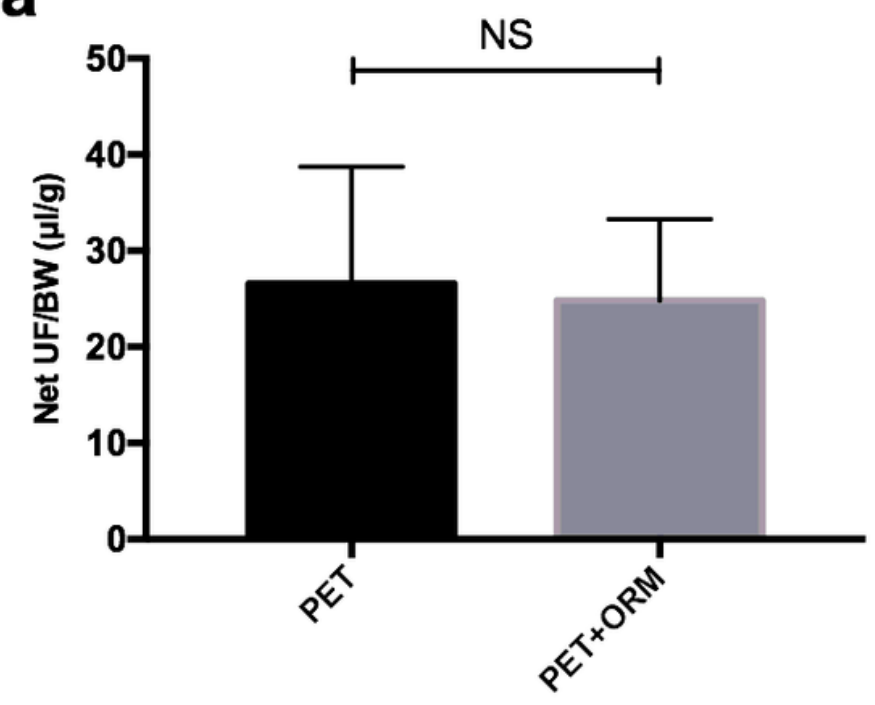

C

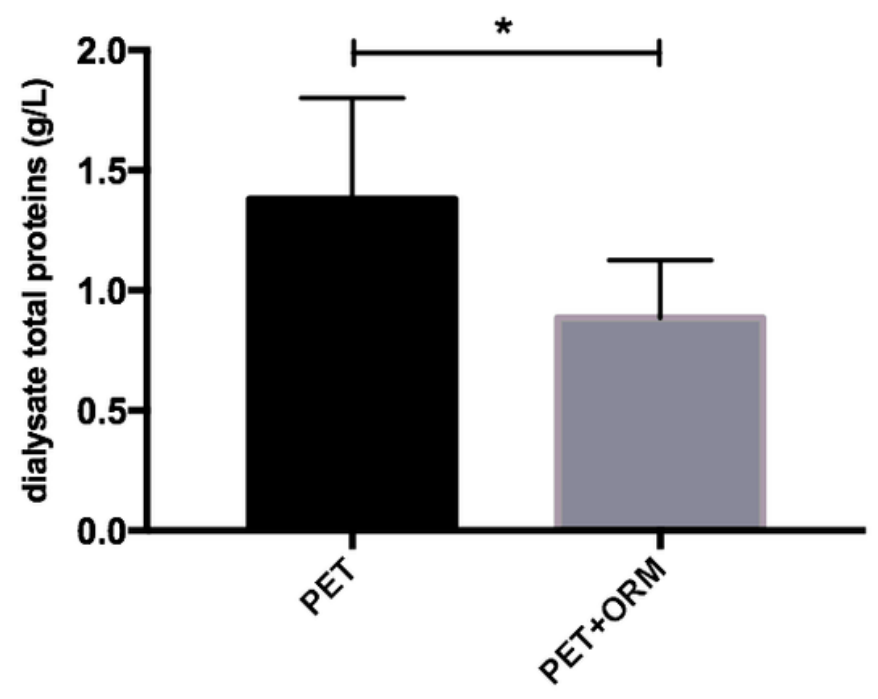

b
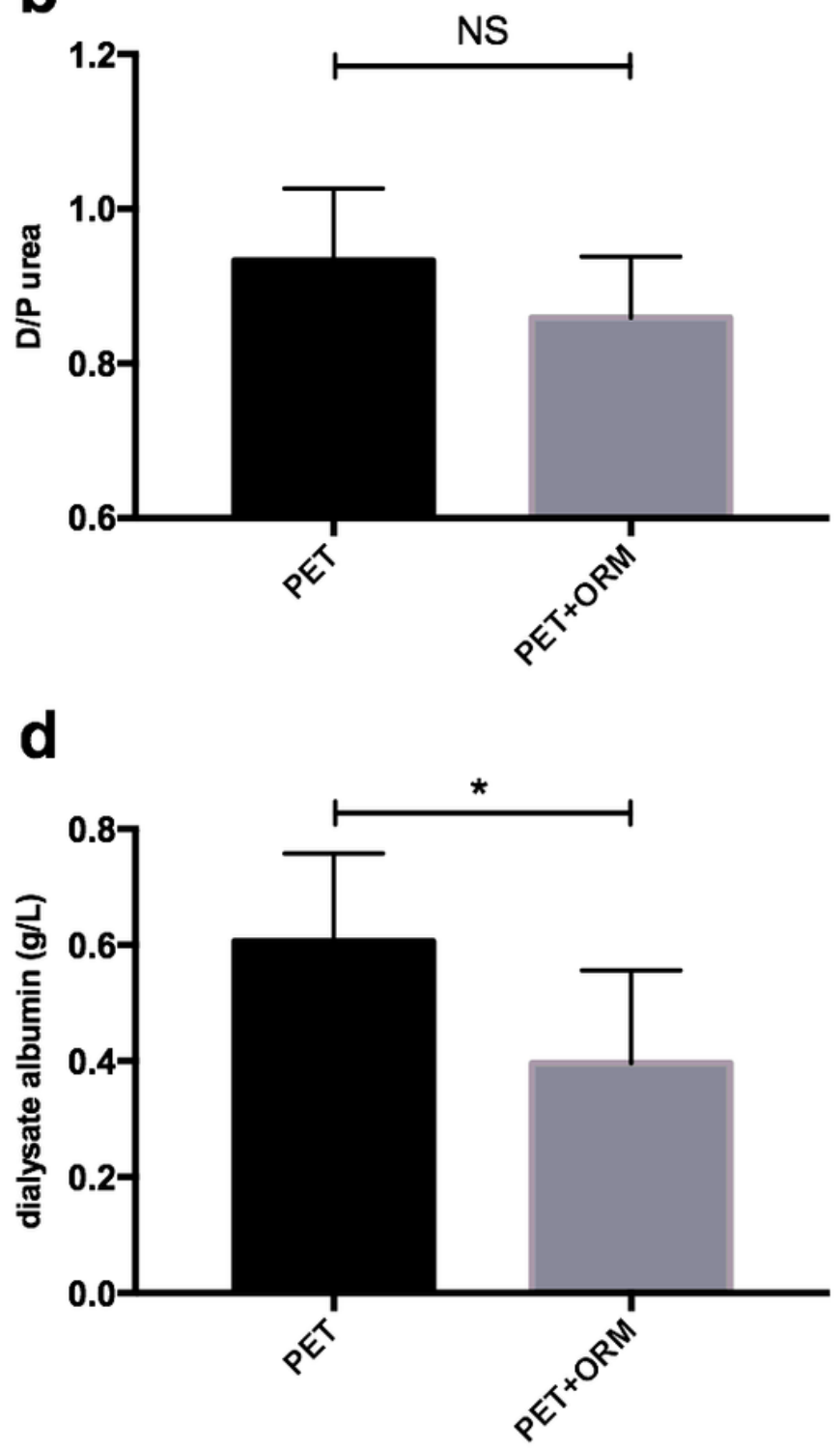

Figure 6

Peritoneal permeability parameters in mice ( $n=6$ for each group). a Net UF/BW. b D/P urea. c dialysate total proteins. $d$ dialysate albumin. UF, ultrafiltration; BW, body weight; NS, non-significant. $\triangle \mathrm{P}<0.05$ 


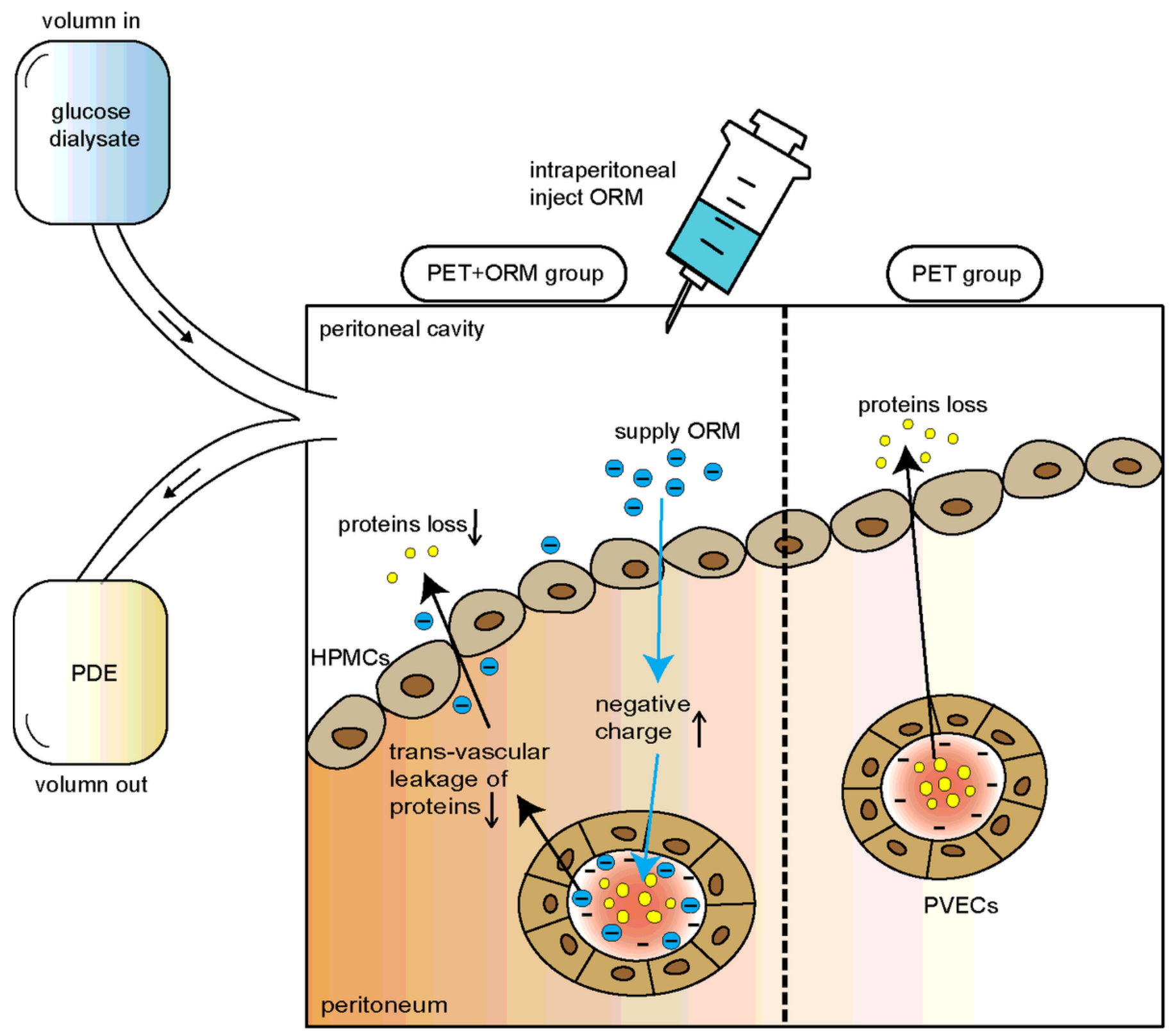

Figure 7

Supplying ORM reduced protein loss during PET by adding more negative charge on the surface of HPMCs and PVECs. PET, peritoneal equilibration test; PDE, peritoneal dialysis effluents; HPMCs, human peritoneal mesothelial cells; PVECs, peritoneal vascular endothelial cells.

\section{Supplementary Files}

This is a list of supplementary files associated with this preprint. Click to download.

- SupplementalTable1.docx

- s1.tif 